\section{Silanated Surface Treatment: Effects on the Bond Strength to Lithium Disilicate Glass-Ceramic}

Samantha Schaffer Pugsley Baratto ${ }^{1}$, Denis Roberto Falcão Spina' ${ }^{1}$ Carla Castiglia Gonzaga ${ }^{1}$, Leonardo Fernandes da Cunha ${ }^{1}$, Adilson Yoshio Furuse ${ }^{2}$, Flares Baratto Filho ${ }^{1}$, Gisele Maria Correr ${ }^{1}$

The aim of this study was to evaluate the effect of silanization protocols on the bond strength of two resin cements to a lithium disilicate glass-ceramic. Thirty-two ceramic discs were assigned to 2 groups ( $n=16)$ : $\mathrm{G} 1$ - dual-cured resin cement and G2 - lightcured resin cement. Four subgroups were evaluated according to the used silanization protocol. The glass-ceramic was etched with 10\% hydrofluoric acid for $20 \mathrm{~s}$ and silane was applied for $1 \mathrm{~min}$, as follows: CTL - according to the manufacturer's instructions; HA - dried with hot air; NWA - washed and dried with water and air at room temperature; HWA - washed and dried with hot water and hot air. Thereafter, adhesive was applied and light-cured for $20 \mathrm{~s}$. Silicon molds were used to prepare resin cement cylinders $(1 \times 1$ $\mathrm{mm}$ ) on the ceramic surface. The specimens were stored in deionized water at $37^{\circ} \mathrm{C}$ for $48 \mathrm{~h}$ and subjected to a micro-shear test. The data were submitted to statistical analysis $(\alpha=0.05)$. Group $\mathrm{G} 1$ showed higher bond strengths than $\mathrm{G} 2$, except for the CTL and NWA subgroups. Differences as function of the silanization protocol were only observed in $\mathrm{G} 1$ : HWA $(25.13 \pm 6.83) \geq \mathrm{HA}(22.95 \pm 7.78) \geq \mathrm{CTL}(17.44 \pm 7.24) \geq \mathrm{NWA}(14.63 \pm 8.76)$. For $\mathrm{G} 2$ there was no difference among the subgroups. In conclusion, the silanization protocol affected the resin cement/ceramic bond strengths, depending on the material. Washing/drying with hot water and/or hot air increased only the bond strength of the dual-cured resin cement.

\author{
'Graduate Program in Dentistry, \\ Department of Operative \\ Dentistry, UP - Positivo \\ University, Curitiba, PR, Brazil \\ ${ }^{2}$ Department of Operative \\ Dentistry, Endodontics and \\ Dental Materials, Bauru Dental \\ School, USP - Universidade de \\ São Paulo, Bauru, SP, Brazil
}

Correspondence: Gisele Maria Correr, Rua Pedro Viriato Parigot de Souza, 5300, 81280-330 Curitiba, PR, Brasil. Tel: +55-41-3317-3456. e-mail:giselenolasco@up.com.br

Key Words: ceramics, shear bond strength, dental cements, dental adhesive.

\section{Introduction}

Clinical success of a ceramic restoration depends on the quality and durability of the bond between ceramic and the resin cement. To achieve adequate cement/ceramic bond strength, many treatments on the ceramic surface can be performed. For adhesive cementation, use of a silane coupling agent (16) is recommended. This is a monomer with reactive organic radicals and a hydro-soluble monovalent group that produces bonding between the inorganic phase of ceramic and the organic phase of bonding agent and is attached to the ceramic surface by a siloxane bond (2). Additionally, the silane agent increases the surface energy of ceramic substrates and improves adhesive and/or cement wettability (2). An appropriate silane protocol should therefore be used to assure the bond strength success and longevity of dental restoration $(1,4,5)$.

When silane is applied on the ceramic surface and then dried, an interphase layer is produced (15). Nevertheless, this surface layer of coupling agent is unnecessary for the bonding process, and may even be detrimental $(14,15)$. Removing the outermost layer of the silane film and leaving the most stable and chemisorbed layer on the ceramic surface improves the bond strength with the restorative interface (14). However, the most effective protocol to remove this layer has not yet been identified.
Recently, heat treatment has been proposed to improve the technique used to apply silane agent. Heat treatment of the ceramic surface may increase the bonding strength with resin cements, since it removes the upper silane layer and improves chemical adhesion $(11,14,17,18,20)$. On the other hand, some studies report no significant improvement arising from the heat treatment $(8,9)$.

For esthetic restorations, lithium disilicate glassceramics are commonly recommended due to their optical properties. Because of their glassy composition, these ceramics are acid-sensitive. Thus, the adhesive protocol for glass-ceramics involves the application of hydrofluoric acid, and then of a silane agent. Thus, an evaluation of the performance of the silane agent on ceramic surfaces becomes imperative $(1,2,4)$.

Cured resin cements with different characteristics (i.e. dual- or light-cured) may be used for the cementation of glass-ceramics. Since the predictability and clinical performance of all-ceramic restorations includes the cementation system, activation type, mechanism and its polymerization time, as well as the type of ceramic material, there is interest to evaluate the influence of alternative silane treatments on the bonding strength of glass-ceramics to cured resin cements with different characteristics, such as dual- or light-cured ones. 
Thus, the aim of this study was to evaluate the effect of different silanization protocols on the micro-shear bond strength of dual-cured and light-cured resin cements to a lithium disilicate glass-ceramic. The hypothesis was that heat treatment of the silane would improve the resin cement/ceramic bond strength.

\section{Material and Methods}

Thirty-two $1 \times 15 \mathrm{~mm}$ heat-pressed lithium disilicate glass-ceramic discs (IPS e.max Press; Ivoclar Vivadent AG, Schaan, Liechtenstein) were fabricated using the lost wax technique according to the manufacturer's instructions. Disc surfaces were flattened with 280 - and 400-grit silicon carbide sandpaper for standardization purposes. The final polishing was performed with 600-grit paper.

The specimens were divided in two groups $(n=16)$ : G1: silane (Silano; Dentsply, Santiago, Chile), adhesive system (Adper Scotchbond; 3M ESPE, St. Paul, MN, USA) and dual-cured resin cement (RelyX ARC, 3M ESPE); G2: silane (Silane, DMG, Hamburg, Germany), adhesive system (Luxa Bond Total Etch; DMG) and light-cured resin cement (Vitique Base; DMG).

All the surfaces of ceramic discs were etched with 10\% hydrofluoric acid (Dentsply) for $20 \mathrm{~s}$, rinsed for $20 \mathrm{~s}$ with water spray, air-dried and silanated. These specimens were then divided into 4 subgroups (for each material; $n=4$ ) according to the silane protocol employed:

- CTL (control): a microbrush was moistened with silane (G1: Silane, Dentsply; G2: Silane, DMG) and applied on the surface for $20 \mathrm{~s}$. The latter was then air-blown with an air syringe for $60 \mathrm{~s}$ at a standard distance of 10 $\mathrm{cm}$. Subsequently, the adhesive was applied (G1: Adper Scotchbond Adhesive, 3M ESPE; G2: Luxa Bond Adhesive, DMG) and light-cured for $20 \mathrm{~s}$.

- HA: a microbrush was moistened with silane (G1: Silane, Dentsply; G2: Silane, DMG) and applied on the surface for $20 \mathrm{~s}$. The latter was then air-blown with a hairdryer (P1 $2000 \mathrm{~W}$; Belissima, Imetec, Italy) for $30 \mathrm{~s}$ $\left(50 \pm 5^{\circ} \mathrm{C}\right)$ at a standard distance of $10 \mathrm{~cm}$. Next, the adhesive was applied (G1: Adper Scotchbond Adhesive, 3M ESPE; G2: Luxa Bond Adhesive, DMG) and light-cured for $20 \mathrm{~s}$.

- NWA: a microbrush was moistened with silane (G1: Silane, Dentsply; G2: Silane, DMG) and applied on the surface for $20 \mathrm{~s}$. The silane was washed in tap water (30 s), dried with an air syringe (30 s) at a standard distance of $10 \mathrm{~cm}$, before the adhesive was applied (G1: Adper Scotchbond Adhesive, 3M ESPE; G2: Luxa Bond Adhesive, DMG) and light-cured for $20 \mathrm{~s}$.

- HWA: a microbrush was moistened with silane (G1: Silane, Dentsply; G2: Silane, DMG) and applied on the surface for $20 \mathrm{~s}$. The silane was washed with hot water $\left(80{ }^{\circ} \mathrm{C}, 30 \mathrm{~s}\right)$, dried with a hairdryer (P1 $2000 \mathrm{~W}$; Belissima) for $30 \mathrm{~s}\left(50 \pm 5^{\circ} \mathrm{C}\right)$. Next, adhesive was applied (G1: Adper Scotchbond Adhesive, 3M ESPE; G2: Luxa Bond Adhesive, DMG) and light-cured for $20 \mathrm{~s}$.

A split silicon mold (1.0 mm diameter; $1.0 \mathrm{~mm}$ high) was clamped to the treated ceramic surfaces and filled with dual-cured (Rely X ARC; 3M ESPE) or light-cured (Vitique Base; DMG) resin cement. Both resin cements were lightcured continuously for $40 \mathrm{~s}$ at $1.100 \mathrm{~mW} / \mathrm{cm}^{2}$ (Poly Wireless; Kavo, Joinville, SC, Brazil). Ten minutes after completion of light curing, the bonded specimens were released from their molds and individually stored in dark canisters filled with distilled water at $37^{\circ} \mathrm{C}$ for $48 \mathrm{~h}$.

Shear bond strengths were tested using a universal testing machine (EMIC DL2000; São José dos Pinhais, PR, Brazil). The wire-loop method was adopted at a crosshead speed of $0.5 \mathrm{~mm} / \mathrm{min}$. Mean values and standard deviations were calculated for each subgroup. Failure modes were evaluated at $57 \times$ under a stereomicroscope (SZX9; Olympus, Tokyo, Japan). Failure was assessed as mainly adhesive, mainly cohesive within the resin cement, or mixed.

Data were submitted to two-way analysis of variance and to Tukey's HSD test, at a significance level of 5\%.

\section{Results}

The mean bond strengths (MPa) and standard deviations measured for each group of specimens are presented in Table 1. There were significant differences in the used material (resin cement) $(p<0.00001)$ and silane protocol $(p=0.002)$. An interaction was also found between the materials and silane protocols $(p=0.0066)$. The dual-cured resin cement led to higher bond strengths than the light-cured resin cement, except in the CTL and NWA subgroups.

There were significant differences among the silane protocol subgroups only for the dual-cured resin cement, where the highest bond strengths were measured for the HWA subgroup and they differed significantly from the CTL and NWA subgroups. The lowest values were obtained

Table 1. Mean bond strengths (in MPa) and the corresponding standard deviations measured by micro-shear bond strength tests for specimens $(n=16)$ of dual-cured and light-cured resin cements attached to a lithium disilicate glass-ceramic prepared using different silanization protocols

\begin{tabular}{lcc}
\hline Silane protocol & Rely X ARC (G1) & Vitique (G2) \\
\hline CTL & $17.44( \pm 7.24)^{\mathrm{bc}}$ & $12.66( \pm 6.79)^{\mathrm{cd}}$ \\
HA & $22.95( \pm 7.78)^{\mathrm{ab}}$ & $10.78( \pm 4.05)^{\mathrm{cd}}$ \\
NWA & $14.63( \pm 8.76)^{\mathrm{cd}}$ & $10.60( \pm 4.40)^{\mathrm{d}}$ \\
HWA & $25.13( \pm 6.83)^{\mathrm{a}}$ & $12.30( \pm 4.55)^{\mathrm{cd}}$ \\
\hline
\end{tabular}

Superscript letters classify the mean values into different groups. Two values without a superscript letter in common are significantly different $(p<0.05)$. 
for the NWA subgroup, but they were not significantly different from those measured for CTL samples. The CTL and $\mathrm{HA}$ specimens produced intermediate bond strength values. Regarding the light-cured resin cement, there were no significant differences among the subgroups.

There were significant differences for failure modes among the groups $(p<0.05)$. Analysis of failure modes showed that cohesive failure prevailed in $\mathrm{G} 1$ (dual-cured resin cement), except for CTL, which presented mostly adhesive failures (Fig. 1). In G2 (light-cured samples), most failures were mixed and adhesive (Fig. 1). CTL and HWA subgroups presented mainly cohesive failures within the resin cement. In contrast, mixed failures prevailed in the HA subgroup, while NWA specimens presented significantly more adhesive failures.

\section{Discussion}

Many factors are involved in the success of resin-bonded ceramic restorations, among which durability and stability of tooth-resin and resin-ceramic interfaces are particularly important. Bond strength at these interfaces should be optimized, as failures in this region can lead to failure of the restoration. has been heat treatment of the silane agent $(3,8,11,13,17$ 20). However, there is no consensus regarding the benefits of silane heat treatment. This lack of consensus was confirmed in the present study, as the effect of the silanization technique was dependent on the used resin cement.

According to the results of this study, there was a significant difference in bond strength in the material, silane protocol and material/silane interaction protocol. In general, higher values were obtained in $\mathrm{G} 1$ than in $\mathrm{G} 2$. However, there was no statistically significant difference between the strength of the $\mathrm{G} 1$ and $\mathrm{G} 2$ samples in the CTL and NWA subgroups. Both combinations of materials

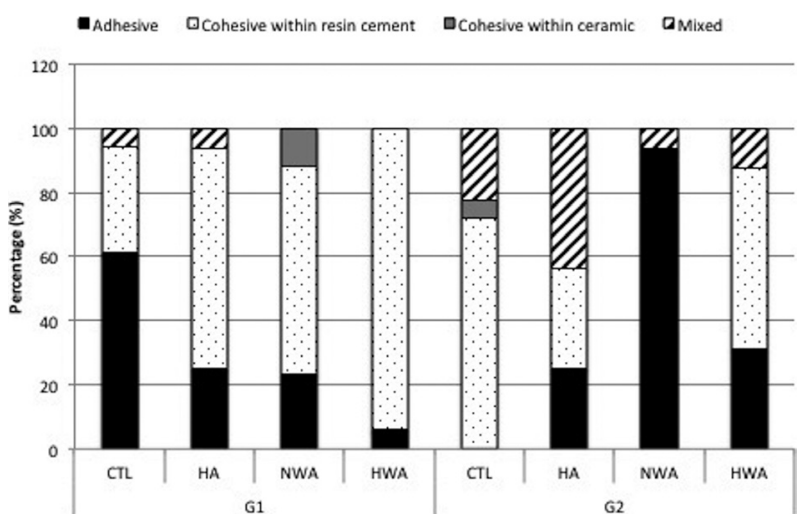

Figure 1. Distribution of failure modes found after micro-shear bond strength test for specimens of dual-cured resin cement group (G1) and for specimens of light-cured resin cement group (G2). (silane/adhesive/resin cement) behaved in a similar manner when applied according to the manufacturers' instructions.

The silanization protocols resulted in different shear bond strengths only for the combination of materials in G1 (Rely X ARC) group, but no effect was observed for the $\mathrm{G} 2$ group (Vitique), thus the hypothesis of this study was rejected. The results of the present study were materialdependent (they varied for different silane/adhesive/resin cement combinations).

The use of hot water and hot air after application of the silane agent (subgroups HWA and HA) led to higher bond strengths than those measured in subgroups CTL and NWA, for the dual-cured resin cement. This is in agreement with the results of other studies that also found improved bond strengths in subgroups where silane was heated after application $(3,8,11,13,17-20)$.

The heating of silane (using hot air) on the surface of the ceramic eliminates water, alcohol, the by-products of the reaction of silane and helps complete the silica-silane condensation, promoting the formation of siloxane $(14,20)$. Evaporation of alcohol or acetic acid may increase the local density of connections available to react with silane solution ceramics (20). Washing with hot water improves the bond strength due to the removal of the upper layers of silane, which are physically attached without covalent bonds, leaving the more stable and chemically bonded silane layer at the bonding interface (14).

No difference in bond strength was measured as function of the silanization technique for the $\mathrm{G} 2$ group. This agrees with other studies that found no significant difference in groups in which silane was heat-treated $(6,8,9)$. Both studies were performed using pre-hydrolyzed silanes. Other studies $(3,21,22)$ found that different types of silane led to different bonding strengths after heat treatment.

The different tendencies reported in the literature may be related to several factors such as silane agents with different compositions (types of solvents) and therefore potentially different reactivity and stability; different silane/adhesive/resin cement combinations and different application methods of silane (temperature of the hot air, heating means, duration of the hot air treatment, washing with hot water, etc.) $(7,19)$. More studies are required to standardize the heating technique employed after application of the silane agent.

Regarding the type of failure, there was difference in the fracture patterns observed between the groups $\mathrm{G} 1$ and $\mathrm{G} 2$. Except for CTL, cohesive failures within the cement prevailed for the dual resin cement subgroups. The percentage of adhesive failures was higher in $\mathrm{G} 2$ than in $\mathrm{G} 1$. This may be related to the type of performed mechanical test. The shear bond strength involves fastening a cement cylinder on a flat ceramic surface, where a complex stress distribution 
is produced during the test $(10,14)$. One should consider however that in clinical situations a combination of shear and tensile stresses may occur at the adhesive interface.

Moreover, there is a relationship between high bond strengths and predominance of cohesive type failures within the cement. Higher bond strengths were measured in $\mathrm{G} 1$ than in G2. According to Hooshmand et al. (14), cohesive failures predominate when the cement interface bond strength exceeds the cohesive strength of cement. When fracture occurs due to cohesive failure within the cement, it is caused mainly by failures within the resin rather than at the interface. This suggests either that interface failures were eliminated because of the improved application method for the silane agent, or that their effect was less important than the inherent strength of resin cement.

The results of this study, confirmed by other studies in the literature $(3,8,11,13,17-20)$, show that heat treating the silane agent after its application on ceramic surfaces may be an important operative step in dental practice. Since both heat treatments (hot water and hot air) were effective with no significant difference between their effects, the authors suggest including only hot-air drying of the silane agent in clinical practice, as the washing protocol would add an extra step to the clinical routine without significantly improving the bond strength.

In conclusion, the silanization protocol affects diversely the resin cement/ceramic bond strength depending on the particular used material combination. Drying the silane agent with hot water and/or hot air only provided higher bond strengths for the dual-cured resin cement.

\section{Resumo}

0 objetivo do estudo foi avaliar o efeito da técnica de silanização na resistência de união de cimentos resinosos a uma vitrocerâmica. Trinta e dois discos de vitrocerâmica foram distribuidos em 2 grupos ( $n=16)(G 1$ : cimento dual e G2: cimento fotoativado) e subdivididos em 4 grupos de acordo com a técnica de silanização. A vitrocerâmica foi condicionada com ácido fluoridrico a 10\% por $20 \mathrm{~s}$ e o silano aplicado por $1 \mathrm{~min}$ de acordo com os subgrupos: CTL: de acordo com as instruções do fabricante, HA: secagem do silano com ar quente, NWA: lavagem e secagem com água e ar a temperatura ambiente, HWA: lavagem e secagem com água e ar quente. Após, o sistema adesivo foi aplicado e polimerizado por 20 $\mathrm{s}$, e cilindros ( $1 \times 1 \mathrm{~mm})$ foram confeccionados com os cimentos sobre a superfície da cerâmica. Os espécimes foram armazenados em água destilada por $48 \mathrm{~h}$ e submetidos ao ensaio de microcisalhamento. Os dados foram submetidos à análise estatística $(\alpha=0,05)$. 0 grupo $\mathrm{G} 1$ apresentou maiores valores de resistência do que $\mathrm{G} 2$, exceto no subgrupo CTL e NWA. Houve diferença na técnica de silanização apenas para $\mathrm{G} 1$ : HWA $(25,13 \pm 6,83) \geq \mathrm{HA}$ $(22,95 \pm 7,78) \geq \operatorname{CTL}(17,44 \pm 7,24) \geq \operatorname{NWA}(14,63 \pm 8,76)$. Para $G 2$ não houve diferença entre os subgrupos. Conclui-se que a técnica de silanização interferiu na resistência de união cimento/cerâmica dependendo do material utilizado. A lavagem e secagem com água e ar aquecidos promoveu maior valor de resistência apenas para o cimento dual.

\section{Acknowledgements}

The authors thank DMG (Hamburg, Germany) for their support for this research.

\section{References}

1. Amaral $R$, Ozcan M, Bottino MA, Valandro LF. Microtensile bond strength of a resin cement to glass infiltrated zirconia-reinforced ceramic: The effect of surface conditioning. Dent Mater 2006;22:283-290.

2. Anusavice KJ. Dental Ceramics. In: Phillip's science of dental materials. Anusavice KJ, Shen C, Rawls H.R. (Editors). 12th ed. Rio de Janeiro: Elsevier; 2013. p 457-459.

3. Bargui N, Berry T, Chung K. Effects of timing and heat treatment of silanated porcelain on the bond strength. J Oral Rehabil 2000;27:407-412.

4. Blatz MB, Sadan A, Kern M. Resin-ceramic bonding: a review of the literature. J Prosthet Dent 2003;89:268-274.

5. Brentel AS, Özcan M, Valandro LF, Alarça LG, Amaral R, Bottino MA. Microtensile bond strength of a resin cement to feldspathic ceramic after different etching and silanization regimens in dry and aged conditions. Dent Mater 2007;23:1323-1331.

6. Carvalho RF, Martins MEMN, Queiroz JRC, Leite FPP, Özcan M. Influence of silane heat treatment on bond strength of resin cement to a feldspathic ceramic. Dent Mater J 2011;30:392-397.

7. Chen TM, Brauer GM. Solvent effects on bonding organo-silane to silica surfaces. J Dent Res 1982;61:1439-1443.

8. Corazza PH, Cavalcanti SC, Queiroz JR, Bottino MA, Valandro LF. Effect of post-silanization heat treatments of silanized feldspathic ceramic on adhesion to resin cement. J Adhes Dent 2013;15:473-479.

9. Cotes $C$, Carvalho RF, Kimpara ET, Leite FPP, Özcan M. Can heat treatment procedures of pre-hydrolyzed silane replace hydrofluoric acid in the adhesion of resin cement to feldspathic ceramic? J Adhes Dent 2013;15:569-574.

10. Della Bona A, Anusavice KJ, Mecholsky JJ Jr. Failure analysis of resin composite bonded to ceramic. Dent Mater 2003;19:693-699.

11. Fabianelli A, Pollington S, Papacchini F, Goracci C, Cantoro A, Ferrari $M$, et al.. The effect of different surface treatments on bond strength between leucite reinforced feldspathic ceramic and composite resin. J Dent 2010;38:39-43.

12. Hooshmand T, Matinlinna JP, Keshvad A, Eskandarion S, Zamani F. Bond strength of a dental leucite-based glass ceramic to a resin cement using different silane coupling agents. J Mech Behav Biomed Mater 2013;17:327-332

13. Hooshmand $T$, van Noort $R$, Keshvad A. Storage effect of a preactivated silane on the resin to ceramic bond. Dent Mater 2004;20:635-642.

14. Hooshmand $T$, van Noort $R$, Keshvad A. Bond durability of the resinbonded and silane treated ceramic surface. Dent Mater 2002;18:179-188.

15. Ishida $\mathrm{H}$. Structural gradient in the silane coupling agent layers and its influence on the mechanical and physical properties of composites. In: Molecular characterization of composite interfaces. Ishida $\mathrm{H}$. and Kumar G. (Editors). 1st ed. New York: Plenum Press, 1985. p 25-50.

16. Matinlinna JP, Vallittu PK. Bonding of resin composites to etchable ceramics surface: An insight review of the chemical aspects on surface conditioning. J Oral Rehabil 2007;34:622-630.

17. Monticelli $F$, Toledano $M$, Osorio R, Ferrari M. Effect of temperature on the silane coupling agents when bonding core resin to quartz fiber posts. Dent Mater 2006;22:1024-1028.

18. Pereira CNB, Buono VTL, Mota JMLM. The influence of silane evaporation procedures on microtensile bond strength between a dental ceramic and a resin cement. Indian J Dent Res 2010;21:238-243.

19. Sakai M, Taira $Y$, Sawase T. Silane primers rather than heat treatment contribute to adhesive bonding between tri-n-butylborane resin and a machinable leucite-reinforced ceramic. Dent Mater J 2011;30:854-860.

20. Shen $\mathrm{C}, \mathrm{Oh}$ WS, Williams JR. Effect of post-silanization drying on the bond strength of composite to ceramic. J Prosthet Dent 2004;91:453-458.

21. Novais VR, Simamoto Júnior PC, Rontani RM, Correr-Sobrinho L, Soares $\mathrm{CJ}$. Bond strength between fiber posts and composite resin core: influence of temperature on silane coupling agents. Braz Dent J 2014;23:8-14.

22. de Rosatto CM, Roscoe MG, Novais VR, Menezes M de S, Soares CJ. Effect of silane type and air-drying temperature on bonding fiber post to composite core and resin cement. Braz Dent J 2014;25:217-224. 